\title{
Comportamento do vigor foliar em seringueira em diferentes fenologias de dossel
}

\author{
José Carlos PEZZONI FILHO ${ }^{1 *}$, Luis Gustavo Frediani LESSA ${ }^{1}$, Roberto FILGUEIRAS ${ }^{2}$, \\ Victor Costa LEDA ${ }^{1}$, Célia Regina Lopes ZIMBACK ${ }^{1}$, Edson Luiz FURTADO ${ }^{1}$
}

\footnotetext{
${ }^{1}$ Faculdade de Ciências Agronômicas, Universidade Estadual Paulista, Botucatu, SP, Brasil.

${ }^{2}$ Departamento de Engenharia Agrícola, Universidade Federal de Viçosa, Viçosa, MG, Brasil. *E-mail: jpezzoni@gmail.com
}

Recebido em agosto/2017; Aceito em junho/2018.

\begin{abstract}
RESUMO: O vigor foliar da seringueira demonstra variação durante o ano, refletindo fases fenológicas que influenciam na produção de látex, além de períodos suscetíveis à doenças e pragas. Assim, objetivou-se avaliar o vigor foliar dos clones GT 1 e RRIM 600 em abril e; em agosto, setembro e outubro, no município de Itiquira - MT, com clima classificado como Aw. Foram avaliados os vigores dos clones GT 1 e RRIM 600 em abril e; em agosto, setembro e outubro, meses precedente a desfolha anual e posterior a reenfolha natural, respectivamente. O vigor foliar foi avaliado baseado no Índice de Vegetação por Diferença Normalizada (NDVI) de imagens do satélite Landsat 5, onde suas médias foram avaliadas pelo teste de Tukey a 5\% de probabilidade, com Delineamento em Blocos Casualizados e dois tratamentos (clones). Na análise, os dois clones apresentaram NDVI em abril com vigor foliar médio, ocorrendo diferença nas médias de NDVI, com maior no RRIM 600. Entre agosto e outubro o vigor foi alto, sem diferença entre o NDVI médio destes clones. O clone GT 1 com idade superior aos 19 anos demonstrou mudança de fenologia foliar em abril. O clone RRIM 600, posterior aos 17 ou 18 anos, demonstrou início de mudança fenológica das folhas em abril.
\end{abstract}

Palavras-chave: Hevea brasiliensis, índice de vegetação, desfolha natural, fenologia.

\section{Behavior of the foliar vigor in seringueira in different phenological periods}

\begin{abstract}
The leaf vigor of the rubber tree shows variation during the year, reflecting phenological phases that influence the production of latex, in addition to periods susceptible to diseases and pests. Thus, the objective was to evaluate the foliar vigor of clones GT 1 and RRIM 600 in April and; in August, September and October, in the municipality of Itiquira - MT, with climate classified as Aw. The vigores of clones GT 1 and RRIM 600 were evaluated in April and; in August, September and October, months preceding the annual defoliation and subsequent to natural refoliation, respectively. The foliar vigor was evaluated based on the Normalized Difference Vegetation Index (NDVI), Landsat 5 satellite images where its averages were evaluated by Tukey test at 5\% probability, with a randomized block design and two treatments (clones). In the analysis the two clones presented NDVI in April with average leaf vigor, occurring difference in NDVI means, with greater in RRIM 600. Between August and October the vigor was high, with no difference between the mean NDVI of these clones. Clone GT 1 older than 19 years showed a change of foliar phenology in April. The RRIM 600 clone, after the age of 17 or 18 years, it showed the beginning of phenological change of leaves in April.
\end{abstract}

Keywords: Hevea brasiliensis, NDVI, natural defoliation, phenology.

\section{INTRODUÇÃO}

A cultura da seringueira, Hevea brasiliensis (Willd. ex Adr. de Jussieu) Mueller-Argovienis, produz o látex ou borracha natural, que tem grande importância para o mercado nacional e para o mundo devido à utilização na fabricação de pneumáticos e mangueiras, luvas cirúrgicas, condutores elétricos, preservativos e fios elásticos, além de centenas de artefatos de grande utilidade (SOUZA, 2007). O consumo mundial de borracha no segundo trimestre de 2017 foi de 3,17 milhões de toneladas. No Brasil, foi em torno de 265 mil toneladas neste mesmo período (ROSSMANN, 2017)

Os hábitos fenológicos de desfolha e reenfolha natural da seringueira apresentam importância para o manejo do mal das folhas, principal problema fitossanitário da cultura (FURTADO, 2008; SAMBUGARO, 2007). A duração da desfolha, intensidade e velocidade da troca de folhas variam de espécie para espécie e de clone para clone (FURTADO, 1996). A planta apresenta período de senescência e queda das folhas por um período de duas a seis semanas em que fica desfolhada. Normalmente, a desfolha natural ocorre no início da estação seca, sendo característica das plantas com mais de 3 anos de idade onde posteriormente ocorre novo fluxo de lançamento, na reenfolha da planta (GASPAROTTO et al., 1997).

Esta característica decídua da planta apresenta importância devido à informação pressuposta nestes dados, que refletem 0 vigor foliar apresentado pelas plantas em determinada época do ano. Assim, demonstra fases da cultura que podem ser suscetíveis a determinadas doenças ou pragas e tem relação com a produtividade de látex.

Os estudos fenológicos permitem acompanhar a floração, frutificação, brotamento e queda de folhas, nas suas mais diferentes e intensas fases. Tem por objetivo o conhecimento do ciclo anual das espécies em estudo, o qual está diretamente relacionado às condições climáticas e ao caráter adaptativo de cada espécie em sua área de dispersão (ANDREIS et al., 2005). 
A fenologia varia dependendo da espécie e é influenciada por fatores como, a temperatura, a iluminação solar, comprimento do dia, umidade do solo, etc, os quais podem variar dependendo da localidade e do período de tempo (BEURS; HENEBRY, 2010).

Para o monitoramento do seringal pode ser utilizado o sensoriamento remoto, o qual possui a metodologia dos índices de vegetação (IVs). Almeida et al. (2015) citaram que estes índices realçam a variação espectral da vegetação por meio da combinação das bandas espectrais do vermelho e do infravermelho próximo (IVP), demonstrando sensibilidade as variações da estrutura do dossel, quando comparado às bandas individuais. Segundo Moise et al. (2010), entre 2 e 10\% da radiação incidente na faixa do visível é refletida pelos tecidos vegetais, já na faixa do infravermelho de 35 a $60 \%$ da radiação é refletida.

Os IVs podem ser utilizados para a medição de longo prazo de mudanças de vegetação, como a sazonalidade das plantas e suas interações com o clima de diferentes anos e dentre os diversos índices, destaca-se o NDVI (Normalized Difference Vegetation Index) ou Índice de Vegetação por Diferença Normalizada (KIM et al., 2010).

O NDVI minimiza efeitos topográficos ao produzir uma escala linear que varia de $-1 \mathrm{a}+1$ (OLIVEIRA et al., 2012), onde valores negativos representam presença de água, 0 (zero) identifica solo exposto e valores próximos a +1 representa resposta espectral das plantas, sendo que quanto mais próximo de +1 maior será o vigor da planta.

Fontana (1995) citou que a variação anual de NDVI em certas regiões, indica impactos regionais causados por alterações nas condições meteorológicas e mudanças fenológicas. Devido ser em função da alta correlação entre NDVI e a taxa assimilatória vegetal, pode ser indiretamente relacionado com o rendimento de culturas.

Desta forma, objetivou-se avaliar o vigor foliar dos clones de seringueira GT 1 e RRIM 600 em diferentes épocas fenológicas do dossel das plantas, utilizando o método do Índice de Vegetação por Diferença Normalizada (NDVI) com imagens do satélite Landsat 5.

\section{MATERIAL E MÉTODOS}

O experimento localizou-se no município de Itiquira - MT, plantio de seringueira com os clones GT 1 e RRIM 600, com áreas de 1.529 e 880 ha, respectivamente. O plantio localizouse nas coordenadas geográficas de $17^{\circ} 17^{\prime} 40,29^{\prime \prime}$ e $17^{\circ} 26^{\prime} 17,73^{\prime \prime}$ de latitude sul e $54^{\circ} 44^{\prime} 28,6^{\prime \prime}$ e $54^{\circ} 44^{\prime} 43,55^{\prime \prime}$ de longitude oeste, bacia do Rio Paraguai.

As áreas de ambos clones eram vizinhas, onde algumas faziam limites entre si, sendo uma plantação continua com diversos clones. As plantas tinham idade entre 11 e 29 anos em 2008, conforme seus respectivos anos de avaliação. Os plantios do clone GT 1 foram entre os anos de 1982 e 1989 e o RRIM 600 foi entre 1979 e 1983 e em 1987, 1989 e 1990

O clima da região segundo a classificação de Koppen é Aw, com inverno seco. Com base no Google Earth a altitude é de 470 a 550 metros. Camargo (2011) citou que a precipitação média na região é de 1700 a $1900 \mathrm{~mm}$, com deficiência no balanço hídrico entre os meses de junho e setembro, com intensidade de 130 a $150 \mathrm{~mm}$ e excesso hídrico de 800-900 $\mathrm{mm}$, entre novembro e abril. A temperatura média é de $24,5^{\circ} \mathrm{C}$, com mínimas e máximas de $17,5^{\circ} \mathrm{C}$ e $30^{\circ} \mathrm{C}$, respectivamente, com o cerrado como vegetação nativa.
Para o monitoramento do vigor foliar do plantio por meio da análise do NDVI, utilizou-se imagens do satélite Landsat 5, órbita 225, ponto 072, obtidas do site http://www.dgi.inpe.br/CDSR/. As análises foram em abril de 2005, 2006, 2007 e 2008 e setembro e outubro de 2001, 2004, 2005 , além de agosto e outubro de 2008. Devido à dificuldade de obtenção de imagens, estas foram definidas conforme sua disponibilidade sem interferência de nuvens, nas épocas analisadas.

Precedente ao pré-processamento das imagens do Landsat 5, efetuou-se a calibração radiométrica, correção atmosférica conforme Chavez Junior (1988) e registro das imagens para posterior cálculo do NDVI. Para o registro das imagens utilizou-se cena georreferenciada Landsat 5 órbita 225, ponto 72 , baseado em 15 pontos de controle e erro RMSE menor que 0,5 pixel. O sistema de coordenadas utilizado foi UTM, datum WGS 84, 21 Sul. Na análise do Índice de Vegetação NDVI foram utilizadas as bandas 3 e 4 do satélite Landsat 5, conforme desenvolveu Rouse Jr. et al. (1974), Equação 1:

$$
N D V I=\frac{(\rho 2-\rho 1)}{(\rho 2+\rho)}
$$

em que: $\rho 1$ são os valores da reflectância no vermelho $(0,55$ $0,70 \mu \mathrm{m})$ e $\rho 2$ no infravermelho próximo $(0,70-1,30 \mu \mathrm{m})$ do espectro eletromagnético dos alvos.

Para as análises do índice de vegetação foi estabelecida uma escala de valores, variando de 1 a 7 e seus diferentes vigores foliares (Tabela 1). O menor valor da escala foi aquele encontrado nas análises do índice NDVI em todos os meses e anos avaliados (2001, 2004, 2005, 2006, 2007, 2008). Após serem analisadas todas imagens, foi observado que o menor valor foi de 0,31 , sendo o parâmetro para definir a menor escala de NDVI.

Tabela 1. Índices de Vegetação NDVI com seus vigores foliares e estádios fenológicos.

Table 1. Vegetation Indices NDVI with their leaf vigors and phenological stages.

\begin{tabular}{cccc}
\hline $\begin{array}{c}\text { Escala } \\
\text { de NDVI }\end{array}$ & $\begin{array}{c}\text { Intervalo de } \\
\text { NDVI }\end{array}$ & $\begin{array}{c}\text { Vigor } \\
\text { Foliar }\end{array}$ & Estádio \\
\hline 1 & 0,31 a 0,40 & muito baixo & $\mathrm{A}$ \\
2 & 0,41 a 0,50 & baixo & $\mathrm{A}$ \\
3 & 0,51 a 0,60 & baixo & B \\
4 & 0,61 a 0,70 & médio & $\mathrm{C}$ \\
5 & 0,71 a 0,80 & médio & $\mathrm{C}$ \\
6 & 0,81 a 0,90 & alto & $\mathrm{D}$ \\
7 & 0,91 a 1,00 & muito alto & $\mathrm{D}$ \\
\hline
\end{tabular}

Hallé et al. (1978) e Sambugaro (2003) classificaram a fenologia da seringueira nos estádios A, B, C e D. Estádio A gema apical anteriormente em repouso, formação de primórdios foliares e de gemas axilares; Estádio B - fase de alongamento, com concentração alta de antocianina, cor avermelhada; Estádio C - folíolos pendentes, flácidos e de cor verde; Estádio D - folíolos em ângulo reto em relação ao pecíolo, folíolos maduros (Tabela 1).

Os dados pluviométricos utilizados na análise do período do presente experimento foram obtidos do satélite TRMM produto TRMM 3B43 ACC.007, devido à ausência de estação meteorológica presente no local. A precipitação foi estimada pelo satélite para uma área, de em torno, de $25 \mathrm{~km}^{2}$, 
abrangendo limites além da área experimental (2.409 ha). Na Tabela 2 são apresentados os índices pluviométricos entre fevereiro e abril de 2005, 2006, 2007 e 2008.

Tabela 2. Dados pluviométricos estimados pelo satélite TRMM entre 2005 e 2008

Table 2. Rainfall data estimated by the TRMM satellite between 2005 and 2008.

\begin{tabular}{cccccc}
\hline \multirow{2}{*}{ Ano } & \multicolumn{2}{c}{ Coordenadas } & \multicolumn{3}{c}{$\begin{array}{r}\text { Dados pluviométricos } \\
\text { (Graus sexagesimais) }\end{array}$} \\
& Latitude & Longitude & Fevereiro & Março & Abril \\
\hline 2005 & $17^{\circ} 21^{\prime} 50$ "S & $54^{\circ} 42^{\prime} 54^{\prime \prime O}$ & 81,9 & 171,1 & 76,1 \\
2006 & $17^{\circ} 21^{\prime} 50^{\prime \prime} \mathrm{S}$ & $54^{\circ} 42^{\prime} 54^{\prime \prime} \mathrm{O}$ & 165,6 & 224,4 & 140,5 \\
2007 & $17^{\circ} 21^{\prime} 50^{\prime \prime} \mathrm{S}$ & $54^{\circ} 42^{\prime} 54^{\prime \prime} \mathrm{O}$ & 175,6 & 78,6 & 74,6 \\
2008 & $17^{\circ} 21^{\prime} 50^{\prime \prime} \mathrm{S}$ & $54^{\circ} 42^{\prime} 54^{\prime \prime} \mathrm{O}$ & 166,3 & 421,9 & 123,8 \\
\hline
\end{tabular}

As precipitações, em mm, utilizadas foram antecedentes dois meses à data avaliada, pois esta época anterior influencia na resposta fenológica das plantas de seringueira. Os dados entre julho e setembro de 2001, 2004, 2005 e 2008 estão apresentados na Tabela 3. Os dados de agosto foram utilizados porque a resposta foliar da planta advém da umidade em períodos antecedentes, podendo ser considerado aqueles do mês anterior. Além de Agosto, os dados de julho foram utilizados, pois conforme Pinheiro; Pinheiro (2014), os meses de julho e agosto apresentam maior demanda hídrica.

Tabela 3. Dados pluviométricos do satélite TRMM entre julho e outubro, em 2001, 2004, 2005 e 2008.

Table 3. Rainfall data from the TRMM satellite between July and October, in 2001, 2004, 2005 and 2008.

\begin{tabular}{ccccccc}
\hline \multirow{2}{*}{ Ano } & \multicolumn{2}{c}{ Coordenadas } & \multicolumn{4}{c}{$\begin{array}{c}\text { Dados pluviométricos } \\
\text { (Graus sexagesimais) }\end{array}$} \\
& Latitude & Longitude & Jul & Ago & Set & Out \\
\hline 2001 & $17^{\circ} 21^{\prime} 50^{\prime \prime} S$ & $54^{\circ} 42^{\prime} 54^{\prime \prime O}$ & 3,2 & 16,8 & 116,7 & 104,9 \\
2004 & $17^{\circ} 21^{\prime} 50^{\prime \prime} \mathrm{S}$ & $54^{\circ} 42^{\prime} 54^{\prime \prime} \mathrm{O}$ & 26,8 & 0,9 & 13,9 & 137,5 \\
2005 & $17^{\circ} 21^{\prime} 50^{\prime \prime} \mathrm{S}$ & $54^{\circ} 42^{\prime} 54^{\prime \prime} \mathrm{O}$ & 6,8 & 4,1 & 92,4 & 137,4 \\
2008 & $17^{\circ} 21^{\prime} 50^{\prime \prime} \mathrm{S}$ & $54^{\circ} 42^{\prime} 54^{\prime \prime} \mathrm{O}$ & 1,8 & 43,7 & 36,1 & 285,7 \\
\hline
\end{tabular}

A delimitação dos talhões dos clones foi realizada posterior ao cálculo do NDVI, sendo desconsiderados os pixels próximos às estradas e talhões vizinhos com outros clones. Desta forma, os pixels espectralmente duvidosos em relação ao clone avaliado foram descartados. As áreas calculadas referentes a cada intervalo de NDVI foram baseados no pixel do Landsat 5, que tem 30 × 30 metros de resolução espacial. Portanto, cada pixel representa $900 \mathrm{~m}^{2}$ na superfície, assim multiplicou-se pelo total de pixels de cada escala e foi encontrada a área das escalas de NDVI's. As médias de NDVI, dos clones GT 1 e RRIM 600, em abril, foram comparadas pelo teste de Tukey a $5 \%$ e, as médias de agosto, setembro e outubro, de ambos os clones, foram avaliadas pelo teste de Tukey a $5 \%$ de probabilidade.

Para a confrontação da precipitação com a fenologia da seringueira (dados de NDVI), foi necessário utilizar as precipitações diárias, obtendo-se dados de temperatura máxima, média e mínima do ar, da estação meteorológica com código 83.410, conforme a Organização Mundial Meteorológica (OMM). Essa estação está localizada no município de Rondonópolis - MT, coordenadas geográficas em graus decimais: -16.45 de latitude Sul e -54.56 de Longitude Oeste, Datum WGS-84. Esses dados foram adquiridos do banco de dados meteorológico do Instituto
Nacional de Meteorologia (BDMEP/INMET), sendo referentes à fevereiro, março e abril, dos anos de 2005, 2006, 2007 e 2008 (Figura 1).
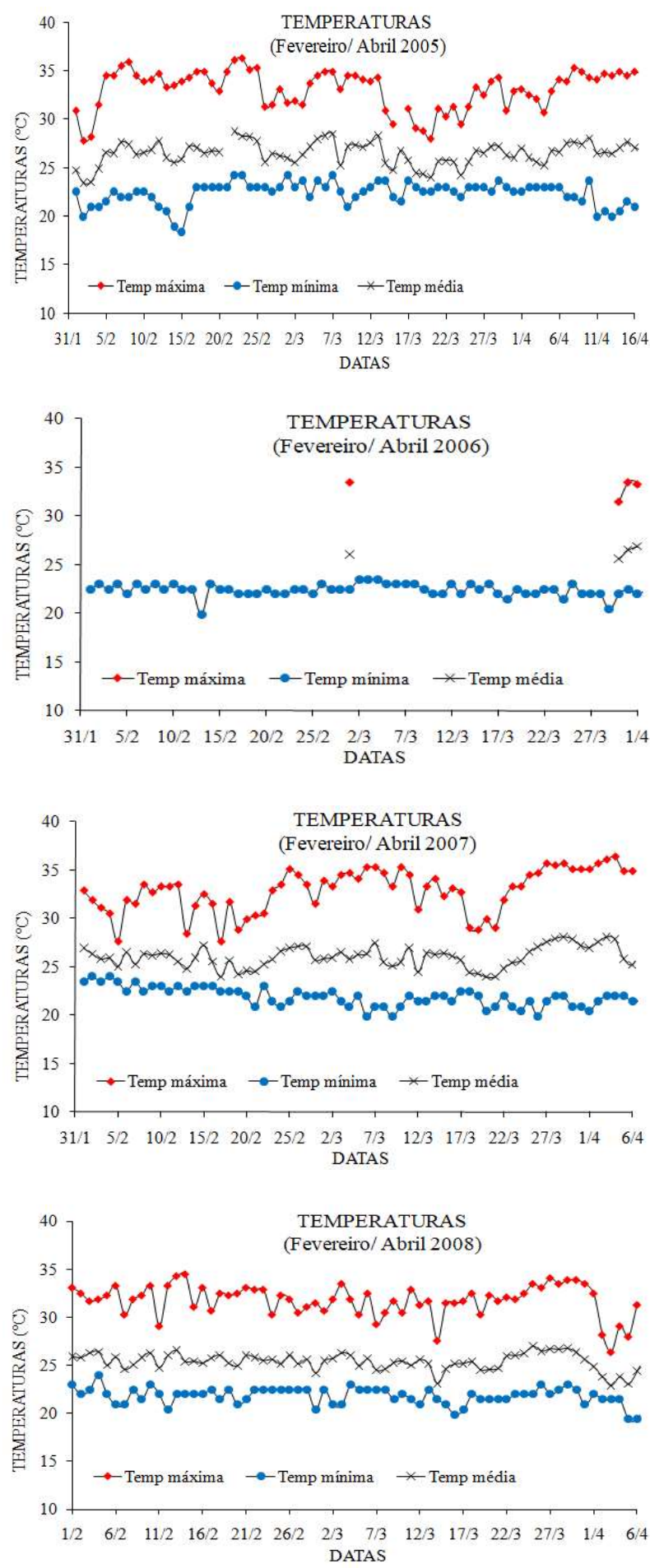

Figura 1. Temperaturas do período antecedente a desfolha anual dos clones, entre os anos de 2005 e 2008.

Figure 1. Temperatures of the period preceding the annual defoliation of the clones, between the years of 2005 and 2008.

Apesar da estação meteorológica encontrar-se a $90 \mathrm{~km}$ do plantio (distância média), os dados podem ser tomados como referência para as análises. A altitude da estação de Rondonópolis é de $290 \mathrm{~m}$, altitude menor que a do seringal, o qual apresenta altitude média de $500 \mathrm{~m}$. Desta forma, pode ser 
considerado que as temperaturas mínimas no plantio podem ser menores que as obtidas na referida estação.

\section{RESULTADOS}

Os NDVI's do clone GT 1 encontrados em abril de 2005 a 2008 se enquadraram nas escalas 3 (NDVI entre 0,51 a 0,60 ), $4(0,61$ a 0,70$), 5(0,71$ a 0,80$)$ e $6(0,81$ a 0,90$)$. No entanto, o resultado com maior expressão em 2005 e 2006 foi a escala 5. A escala 4 foi maior em 2007 e 2008, com 1.099,98 ha e 919,89 ha, respectivamente, sendo que esta escala ficou inferior à encontrada após o reenfolhamento, onde predominou NDVI próximo a +1 , no segundo semestre de cada ano. Em abril, o clone GT 1 apresentou maiores porcentagens na escala $5(\mathrm{NDVI}=0,71$ a 0,80$)$ em 2005 e 2006 , e em 2007 e 2008 a maior escala foi a $4(\mathrm{NDVI}=0,61$ a 0,70$)$, sendo que nestas duas escalas o vigor foliar do plantio foi médio (Figura 2).
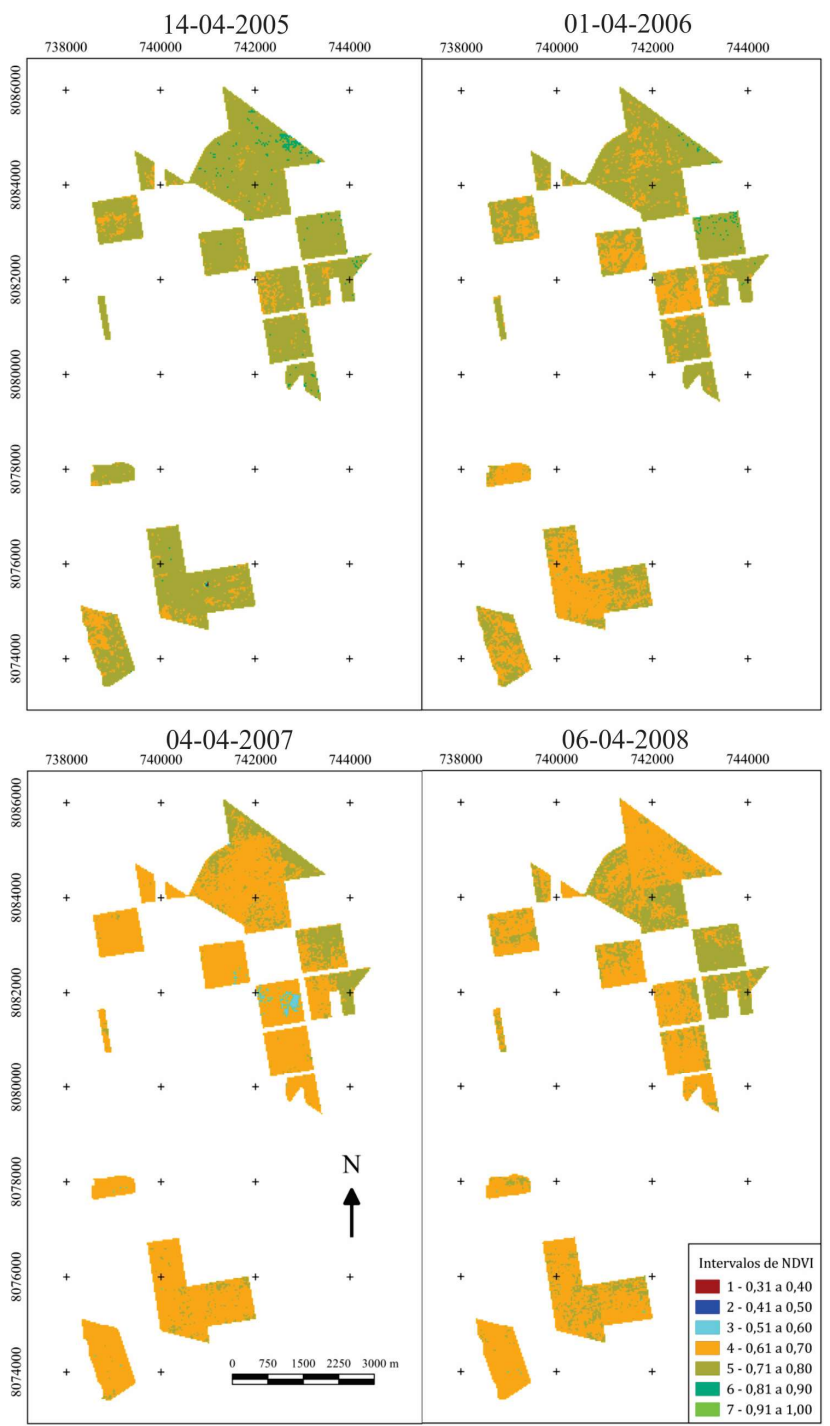

Figura 2. Distribuição espacial do NDVI no período antecedente à desfolha natural do clone GT 1, em abril de 2005 a 2008.

Figure 2. Spatial distribution of NDVI in the period prior to the natural defoliation of clone GT 1, from April 2005 to 2008.

Na reenfolha do clone GT 1, a variação de índice de vegetação, entre setembro e outubro em 2001, apresentou redução de $6,36 \%$ de área na escala 5 e aumentou $5,92 \%$ na escala 6. O NDVI da escala 5, em setembro e outubro, apresentaram 251,64 ha e 162,09 ha, respectivamente, e para a escala 6 foram de 1.155,51 ha em setembro e 1.238,67 ha em outubro. O NDVI entre 0,81 e 0,90 encontrado nas datas de 02-09-2004 e 04-10-2004, se enquadraram na escala 6 , com praticamente $100 \%$ da área em setembro e acima de $90 \% \mathrm{em}$ outubro (Figura 4).

Em abril, o clone RRIM 600 apresentou as escalas 4, 5 (vigores médios) e 6 - vigor alto (Tabela 1), sendo que predominou a escala 5, com 87,32\% (657,54 ha), 92,30\% (696,60 ha), 97,56\% (737,28 ha) e 94,69\% da área total (710,82 ha), nos dias 14-04-2005, 01-04-2006, 04-04-2007 e 06-04-2008, respectivamente (Figura 3). Em abril de 2005, a escala 6 apresentou maior porcentagem de área nos quatro anos, com 10,67\% (80,37 ha), seguido pelos anos de 2006, 2007 e 2008 , com 7,63\% (57,60 ha), 0,72\% (5,40 ha) e $0,32 \%$ da área total $(2,43 \mathrm{ha})$, respectivamente.
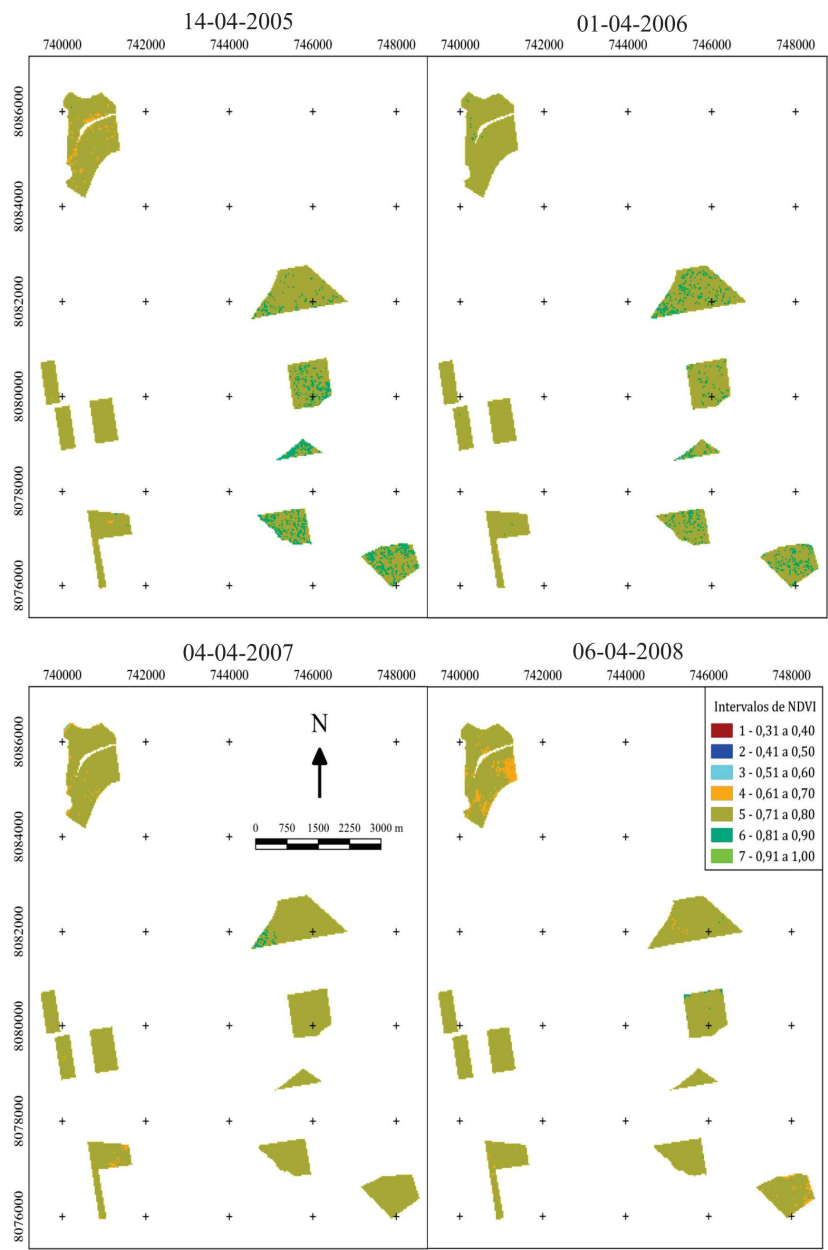

Figura 3. Distribuição espacial do NDVI no período antecedente à desfolha natural do clone RRIM 600, em abril de 2005 a 2008.

Figure 3. Spatial distribution of NDVI in the period prior to the natural defoliation of clone RRIM 600, from April 2005 to 2008.

As escalas do clone RRIM 600, entre 10-09 e 12-10-2001 foram a 5 e 6 , sendo que a segunda foi predominante nos meses em questão. A escala 6 apresentou 72,6\% (653,4 ha) e 99,39\% da área total $(747,9$ ha) para setembro e outubro, respectivamente. Nas datas de 02-09 e 04-10-2004, o clone RRIM 600 apresentou somente as escalas 5 e a 6 , sendo esta última predominante, com 99,06\% (747,45 ha) e 99,82\% da área total $(749,25 \mathrm{ha})$ em setembro e outubro, respectivamente (Figura 5). Em 2005 ocorreram as escalas 5 e 6 no clone RRIM 600 , onde os valores encontrados para a escala 6 foram $86,09 \%$ (645,30 ha) e $98,61 \%$ da área total (742,32 ha) em setembro e outubro, respectivamente. No ano de 2008, o clone RRIM 600 
apresentou variação mínima entre as porcentagens de área na escala 6 , com 750,06 ha $(99,61 \%$ da área) e 739,8 ha $(98,34 \%$ da área total) na data de 28-08-2008 e 15-10-2008, respectivamente.

O teste de Tukey a $5 \%$ de probabilidade das médias de NDVI do clone GT 1 e RRIM 600, em abril e nos meses de agosto, setembro e outubro, estão apresentados na Tabela 4.

Tabela 4. Médias de NDVI dos clones analisadas pelo teste de Tukey a $5 \%$ de probabilidade.

Table 4. NDVI means of the clones analyzed by the Tukey test at $5 \%$ probability.

\begin{tabular}{cccc}
\hline \multirow{2}{*}{ Tratamentos/ Clones } & \multicolumn{3}{c}{ Médias de NDVI } \\
\cline { 2 - 4 } & \multicolumn{2}{c}{ Abril } & Ago-Out \\
\hline RRIM 600 & 0,755 & $\mathrm{a}^{1}$ & $0,84375 \mathrm{a}^{1}$ \\
GT 1 & 0,705 & $\mathrm{~b}$ & $0,84750 \mathrm{a}$ \\
\hline
\end{tabular}

${ }^{1}$ Letras iguais, na mesma coluna, não diferem entre si ao nível de $5 \%$ de probabilidade pelo teste de Tukey.

\section{DISCUSSÃO}

\subsection{Clone GT 1}

O clone GT 1 apresentou escalas com vigor foliar médio (Figura 2) no mês de abril durante os quatro anos, sendo dentro dos intervalos de NDVI entre 0,61 e 0,80, com estádio C, conforme Hallé et al. (1978) e Sambugaro (2003). Este comportamento ocorreu devido a proximidade com a hibernação da seringueira, onde a planta reduz seu vigor foliar.

Neste clone, a maior porcentagem de NDVI na escala $5 \mathrm{em}$ 2005 e 2006 demonstram que nesta época o clone começa a diminuir o vigor foliar, se preparando para a hibernação anual da planta. Desta forma, este fato é confirmado por GuardiolaClaramonte et al. (2008), que descreveram que a seringueira é uma árvore semidecídua, devido as folhas caírem por um curto período de 2 a 4 semanas, mas retém a folhagem durante o restante do ano.

No mês de abril de 2005 e 2006, alguns pixels nas escalas 3 e 4 (Figura 2) podem ter ocorrido devido à influência da infestação pelo nematoide Meloidogyne exigua raça 3, sendo estes os menores valores de escala (vigor vegetativo) para o período analisado. No entanto, esta suposição não pôde ser verificada, além do fato agravante de que cada pixel pode representar mais de 40 árvores no plantio, desta forma, ocorre mistura de respostas espectrais de árvores com e sem sintoma da nematose.

Com base na média de NDVI, onde houve redução da escala 5 (2005 e 2006) para a 4 (2007 e 2008), supõem-se que ocorreu alteração da fenologia, pois a pluviosidade entre fevereiro e março de 2007 foram de 175,6 mm e 78,6 mm, respectivamente (Tabela 2), e nestes mesmos dois meses de 2008 precipitaram $166,3 \mathrm{~mm}$ e $421,9 \mathrm{~mm}$, fato que não interferiu na desfolha.

A temperatura mínima média no plantio, com base nos dados da estação de Rondonópolis, se apresentaram, provavelmente, pouco inferiores a $20^{\circ} \mathrm{C}$. Este fato pode ser considerado, pois esta estação localiza-se a $90 \mathrm{~km}$ ao norte do plantio, e em altitude de $210 \mathrm{~m}$ inferior que a região do seringal. Desta forma, esta diferença de altitude influencia na presença de temperaturas mínimas, sendo que as temperaturas no plantio podem ter influenciado na queda do vigor do dossel das plantas, devido ao fato da temperatura inferior ideal para a cultura ser de $20^{\circ} \mathrm{C}$, conforme citou Ortolani (1986).

Entretanto, as temperaturas inferiores apresentaram pouca variação no período precedente as datas avaliadas durante os 4 anos (Figura 1). Assim, estes dados corroboram com os autores RAO et al., (1998); CHANDRASHEKAR et al., (2002); RAJ et al., (2005), os quais descrevem que a temperatura demonstra importância secundária na seringueira.

Este fato demonstra que mesmo com pouca variação de temperatura mínima entre os dias antecedentes aos dias analisados, houve modificação no metabolismo das plantas. Portanto, observando-se os NDVI's encontrados pode ser considerado que com 19 anos de idade o clone muda de fenologia e adianta sua desfolha anual. Com isso, haverá menor explotação do seringal pelo heveicultor, reduzindo sua renda mensal.

Para o período de reenfolhamento, a oscilação de áreas das escalas 5 e 6 entre setembro e outubro de 2001 foram pequenas, sendo classificadas como estádio D (Tabela 1) conforme Hallé et al. (1978) e Sambugaro (2003). A baixa variação de NDVI entre os dois meses demonstrou que a oscilação do vigor foliar posterior ao reenfolhamento sofreu poucas influencias, provavelmente devido à estresses bióticos ou abióticos, sem identificação (Figura 4).

No período pós reenfolha de 2004, a escala 6 ocorreu em área superior a $90 \%$ dos talhões, em ambos os meses, indicando que as plantas estão com vigor alto. GuardiolaClaramonte et al. (2008) descreveram que análises de campo detectaram que durante o período de desfolha natural, absorção significativa de água ocorre por meio de raízes profundas no subsolo. Este fato foi confirmado na presente análise, pois em agosto e setembro de 2004 houveram somente 0,9 e $13,9 \mathrm{~mm}$ de precipitação e mesmo assim as plantas apresentaram vigor foliar alto. Em 2004, a diferença de NDVI entre setembro e outubro foi pequena, mais de $90 \%$ da área total ficou com vigor alto, escala 6 (Tabela 1), sendo que somente parte de um talhão, coordenadas UTM 21S 8078000 L/ $739000 \mathrm{~N}$, ficou com vigor médio - estádio C (Tabela 1) escala 5 (Figura 4).

Para 2005, a escala predominante em setembro foi a 6 , porém, no talhão mais ao sul do clone GT 1, apresentou mais da metade com vigor médio (NDVI $=0,71$ a 0,80$)$. Entretanto, em outubro o vigor aumentou de médio para alto (escala 6), devido ao reenfolhamento tardio das plantas, fato que pode ser fundamentado devido à deriva de produtos fitossanitários utilizado em áreas vizinhas, nas culturas anuais (Figura 4).

$\mathrm{Na}$ análise de NDVI do dia 28-08-2008 ocorreram as escalas 6 e 7, ambas no estádio fenológico D (Tabela 1), conforme Hallé et al. (1978) e Sambugaro (2003), com 96,52\% da área $\left(1.353,06\right.$ ha) e 3,22\% da área $\left(451,8 \mathrm{~m}^{2}\right)$, respectivamente. Em outubro de 2008 ocorreram as escalas 5 e 6 , com $2,60 \%$ da área $\left(364,5 \mathrm{~m}^{2}\right)$ e $97,29 \%$ da área $(1.363,86$ ha), respectivamente (Figura 4). O NDVI em agosto se apresentou com maior vigor vegetativo, pois ocorre o auge de reenfolha, no entanto, a variação da escala 6 entre agosto e outubro variou somente $0,77 \%$.

O aumento verificado para a escala 5 em agosto de 2008 foi praticamente ausente, e em outubro com 2,60\% da área, sugere-se que as plantas podem ter sofrido algum estresse, pois foi de forma localizada e progressiva no talhão descrito. Uma possível explicação seria a incidência do $M$. exigua raça 3 ou o ataque de percevejo de renda (Leptopharsa heveae) no local. O L. heveae ocorre na área do seringal analisado no período entre agosto e janeiro, conforme citaram Santos; Silva (2013), sendo que o NDVI calculado foi dentro deste período. 

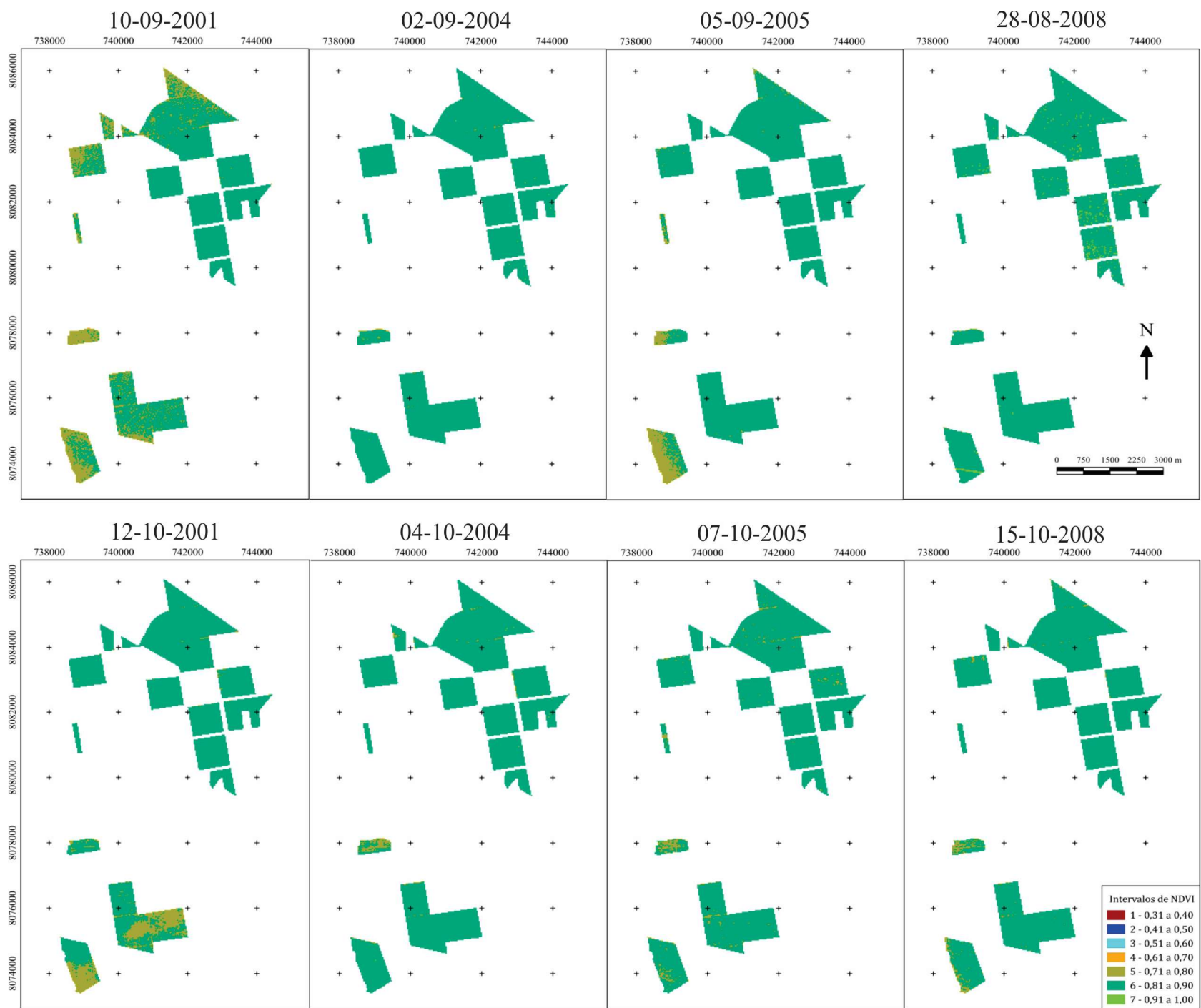

Figura 4. Distribuição espacial do NDVI no período posterior ao reenfolhamento natural do clone GT 1, nos anos de 2001, 2004,2005 e 2008. Figure 4. Spatial distribution of NDVI in the period after the natural refoliation of clone GT 1, in the years 2001, 2004, 2005 and 2008.

\subsection{Clone RRIM 600}

Em abril dos quatro anos, o clone RRIM 600 demonstrou vigor foliar médio e alto, onde o vigor predominante foi o médio, escala 5 (Figura 3). Estes dados demonstraram que a partir de abril começa a diminuição do vigor foliar deste clone, iniciando o período de desfolha anual, fenologia que ocorre na área de escape ao mal das folhas (Microcyclus ulei). A soma do acumulado de chuva em fevereiro e março de 2005, 2006, 2007 e 2008 foi de $253 \mathrm{~mm}, 390 \mathrm{~mm}, 254,2 \mathrm{~mm}$ e 588,2 mm, respectivamente (Tabela 2 ), os quais não influenciaram a diminuição do vigor foliar para a escala 5 (NDVI entre 0,71 e 0,80), estádio C (Tabela 1), conforme Hallé et al. (1978) e Sambugaro (2003).

$\mathrm{O}$ vigor foliar médio predominante em abril sugere que a fenologia de dossel do clone RRIM 600, começa a se modificar para entrar no período anual de desfolha das plantas (Figura 3). Conforme foi comentado, mesmo com o acumulado de chuvas antes de abril houve início da diminuição do vigor foliar.

Em abril de 2005 foi o ano que a escala 6 apresentou maior área dentre os quatro anos em questão, sendo que esta escala pode ser classificada como estádio D (Tabela 1), conforme Hallé et al. (1978) e Sambugaro (2003).

Os dados pluviométricos de 2005, precedente a abril, foram de $81,9 \mathrm{~mm}$ e $171,1 \mathrm{~mm}$, em fevereiro e março, respectivamente. Comparando-se com as chuvas de 2006 e 2008, por exemplo, em 2005 o índice pluviométrico foi menor, com isso, pôde-se concluir que a fenologia das plantas começou a mudar com mais de 17 ou 18 anos, pois a escala 6 praticamente não ocorreu em abril de 2007 e 2008 (Figura 3).

Estas alterações fenológicas no período citado não foram por influência da pluviosidade, onde a melhor hipótese é devido à genética do clone. Este dado é certificado com outros trabalhos, os quais descrevem que precipitação e temperatura desempenham, na melhor das hipóteses, papel secundário na fenologia de $H$. brasiliensis (RAO et al., 1998; CHANDRASHEKAR et al., 2002; RAJ et al., 2005). Confirmando com estes autores citados, a temperatura não influenciou as plantas, conforme pode ser visualizada relativa estabilidade de temperatura mínima na época antecedente as datas avaliadas em abril (Figura 1) 
A quadra no extremo norte, nas coordenadas UTM 21S $8085000 \mathrm{~L} / 741000 \mathrm{~N}$, foi plantada em 1987, no qual, de forma geral, pôde ser observada ausência da mudança fenológica, com exceção de áreas com presença de NDVI entre 0,61 e 0,70 nos anos de 2005 e 2008.

Entretanto, nos talhões entre as coordenadas UTM $21 \mathrm{~S}$ $8083000 \mathrm{~L} / 745000 \mathrm{~N}$ e UTM 21S $8076000 \mathrm{~L} / 749000 \mathrm{~N}$ a escala 6 de NDVI foi ausente em 2007 e 2008, onde a idade das plantas foram de 18 e 19 anos, respectivamente. Este fato pode ser explicado devido a mudança fenológica no clone, posteriormente à idade de 18 anos.

Para as três quadras plantadas em 1990, no extremo sudeste da área de estudo, houve ausência de NDVI entre 0,81 e 0,90 (escala 6). A escala 4, vigor médio - estádio C (Tabela 1), demonstrou $4,99 \% ; 2,01 \% ; 1,73 \%$ e $0,07 \%$ da área total em 2008, 2005, 2007 e 2006, respectivamente, sendo áreas pequenas. Porém, assim podem ser monitorados os estresses no plantio para futuras medidas de manejo (Figura 3).

Em setembro e outubro de 2001 ocorreram vigores médios e altos, porém, com predominância do vigor alto, sendo superiores à $72 \%$ da área total nos dois meses citados. Desta forma, o reenfolhamento das plantas em setembro atrasou, onde, nas bordaduras de alguns talhões sofreram influência do uso do solo da propriedade vizinha (tratos culturais de lavouras) (Figura 5).

Em outubro, praticamente todas as plantas estavam reenfolhadas e sem presença de estresses. Próximo ao 'talhão norte' localiza-se o ribeirão Sozinho. Possivelmente, da área de preservação permanente do referido ribeirão, houve migração de alguma praga ou doença que colonizou somente esta região, sendo assim fonte de inóculo, atrasando o início de seu reenfolhamento em 2001 (Figura 5).
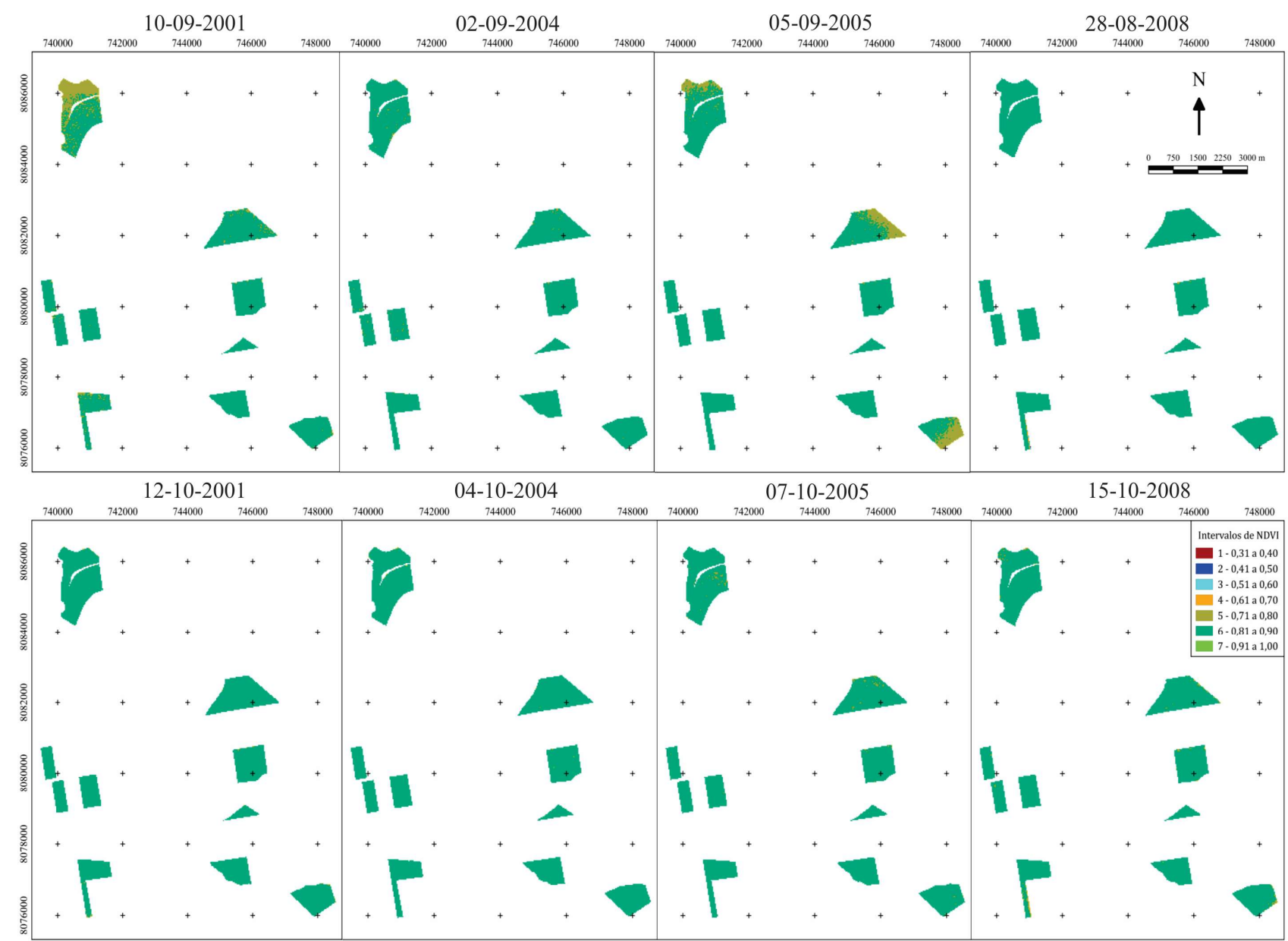

Figura 5. Distribuição especial do NDVI no período posterior ao reenfolhamento natural do clone RRIM 600, nos anos de 2001, 2004, 2005 e 2008.

Figure 5. Spatial distribuition of NDVI in the period after the natural refoliation of the RRIM 600 clone, in the years 2001, 2004, 2005 and 2008.

O NDVI predominante em setembro e outubro de 2004 foi dentro da escala 6 , com valores superiores a $99 \%$ da área total (Figura 5). Neste período analisado a variação de escala foi insignificante, sendo que em outubro não ocorreu possíveis estresses, pois de setembro para outubro foi mantida a mesma escala 6, classificada como vigor alto. A interferência das chuvas neste período foi ausente, pois em agosto e setembro precipitaram 0,9 $\mathrm{mm}$ e 13,9 $\mathrm{mm}$, respectivamente (Tabela 3 ), que não atrapalharam no reenfolhamento esperado das plantas.
A absorção de água subterrânea no período de desfolha é necessária para aumentar o potencial de água no tronco, para superar determinado limite de estimulação da brotação de folhas na planta (BORCHERT et al., 2002). Chandrashekar et al. (1998), estudou plantas localizadas no norte da Índia, as quais demonstraram aumento da circunferência do tronco em várias semanas antes da primeira precipitação. Os autores citaram que este fato pode ser devido à absorção de água do subsolo que está associada a brotação da planta posterior a desfolha anual. 
No ano de 2005, a escala 6 predominou em área total acima de $86 \%$ em setembro e outubro. Em contrapartida, a escala 5 apresentou 13,92\% (104,31 ha) e 1,39\% da área total $(10,44$ ha) em setembro e outubro (Figura 5), respectivamente. Nos locais que apresentaram a escala 5 em setembro, em outubro foram classificados na escala 6 , assim, foi verificado que as plantas finalizaram seu reenfolhamento.

No mês de setembro de 2005, a escala 5, vigor foliar médio, foi encontrada nos talhões que fazem limite com fazendas de culturas anuais, localizados no extremo nordeste e sudeste e, em uma pequena área na porção norte, sendo próximo a área de preservação permanente (APP) do ribeirão Sozinho (Figura 5). Nesta região de escala 5, o atraso na reenfolha pode ter ocorrido devido a fatores que advém dos tratos culturais de lavouras presentes na área lindeira, como por exemplo, deriva de aplicações aéreas e/ ou terrestre.

$\mathrm{Na}$ quadra presente no extremo norte do plantio podem ter ocorrido os mesmos fatores citados para o ano de 2001, entretanto, com menor intensidade em 2005. Já, os outros dois talhões, mês 09/2005, podem ter sofrido efeito bordadura de algum manejo cultural realizado na lavoura vizinha (Figura 5), prolongando ou adiantando a hibernação da planta, que, por consequência, reflete no parcial ou total reenfolhamento do seringal em setembro.

Em outubro de 2005 ocorreram pontos esparsos no plantio com a escala 5, demonstrando algum tipo de estresse (abiótico ou biótico), no entanto, ocorreu o pico do vigor foliar no clone RRIM 600, escala 6 (vigor alto) (Figura 5). Este aumento no vigor vegetal demonstrou que por alguma influência, citadas nos parágrafos anteriores, ocorreu atraso na reenfolha das plantas localizadas nestas coordenadas geográficas.

Em 2008 praticamente foi ausente a variação de escalas, entre o fim de agosto e outubro, prevalecendo o vigor foliar alto (escala 6). Em outubro apareceram algumas falhas do dossel com a escala 5 , com 12,33 ha $(1,64 \%$ da área), sendo que em agosto houve somente 1,62 ha nesta escala $(0,22 \%$ da área total), podendo ser ocasionadas por algum tipo de estresse, sendo desprezível neste caso (Figura 5).

A análise estatística dos dados médios de NDVI de abril, entre os clones GT 1 e RRIM 600, demonstraram que ocorreu diferença a $5 \%$ de probabilidade, pelo teste de Tukey. No clone GT 1 houve menor valor médio de NDVI (NDVI = 0,705), conforme pode ser visualizado na Tabela 4 e na Figura 2. O NDVI demonstrado posterior ao ano de 2006 configurou que ocorreu mudança fenológica neste clone, onde plantas com idade superior a 19 anos foram aquelas que mudaram de escala de NDVI, adiantando seu processo de senescência natural. Condição oposta ocorreu com o clone RRIM 600, que mesmo com talhões mais velhos que o GT 1, demonstrou relativa estabilidade de escala de NDVI predominante (Figura 3).

No teste de médias com dados de NDVI posteriores à reenfolha, foram detectados maiores áreas de estresses em setembro no clone RRIM 600 e em outubro, praticamente foi ausente. Para o clone GT 1, houveram índices na escala $5 \mathrm{em}$ setembro e outubro (Figura 4), sendo áreas estressadas sem identificação do agente etiológico. Assim, ocorreu determinado equilíbrio de valores médios de NDVI em setembro e outubro em ambos os clones, resultando na igualdade estatística encontrada no teste de tukey (Tabela 4).

O NDVI médio dos clones GT 1 e RRIM 600 em setembro e outubro, de forma geral, demonstraram estabilidade dentro do vigor alto (escala 6), as exceções foram locais com NDVI na escala 5 (vigor foliar médio), devido a interferências de estresses sem identificação (Figuras 4 e 5).

O reenfolhamento do seringal no município de Itiquira MT ocorreu de forma adiantada ao que ocorre no Estado de São Paulo, conforme citou Camargo et al. (1976). Estes autores citaram que nas condições climáticas Paulista foram observados que o primeiro fluxo foliar da seringueira aparece normalmente em agosto e setembro, após a dormência e queda das folhas, independentemente da ocorrência de chuvas. A dormência das plantas dá-se em julho e agosto. Nas plantas adultas, o primeiro fluxo foliar surge em todos os galhos ao mesmo tempo e os demais fluxos vêm, em geral, apenas nos galhos apicais. Logo nos primeiros fluxos, as seringueiras foram totalmente enfolhadas.

\section{CONCLUSÕES}

Os clones GT 1 e RRIM 600 demonstraram vigor foliar médio em abril. Já o NDVI médio nos meses de agosto, setembro e outubro, apresentaram vigor alto em ambos os clones;

Com idade superior aos 19 anos, o clone GT 1 demonstrou alteração no vigor em abril, resultando em mudança na sua fenologia foliar;

Posterior aos 17 ou 18 anos, no clone RRIM 600 predominou vigor foliar médio em abril, demonstrando possível início de mudança fenológica do dossel;

Em ambos os clones foram identificados locais com interferências de manejo de plantios limítrofes, entre agosto e outubro;

Em abril, o vigor foliar do clone RRIM 600 foi mais uniforme quando comparado ao clone GT 1 e, posterior a reenfolha, apresentou semelhança entre ambos os clones.

\section{REFERÊNCIAS}

ALMEIDA, A. Q.; RIBEIRO, A.; DELGADO, R. C.; RODY, Y. P., OLIVEIRA, A. S., LEITE F. P. Índice de Área Foliar de Eucalyptus Estimado por Índices de Vegetação Utilizando Imagens TM - Landsat 5. Floresta e Ambiente, Seropédica, v. 22, n. 3, p. 368-376, jul./set. 2015. DOI: http://dx.doi.org/10.1590/2179-8087.103414

ANDREIS, C.; LONGHI, S. J.; BRUN, E. J.; WOJCIECHOWSKI, J. C.; MACHADO, A. A.; VACCARO, S.; CASSAL, C. Z. Estudo fenológico em três fases sucessionais de uma floresta estacional decidual no município de Santa Tereza, RS, Brasil. Revista Árvore, Viçosa, v. 29, n. 1, p. 55-63, jan./ fev. 2005. DOI: http://dx.doi.org/10.1590/S0100-7622005000100007

BEURS, K. M.; HENEBRY, G. M. Spatio-temporal statistical methods for modelling land surface phenology. In: HUDSON, I.; KEATLEY, M. (Eds.) Phenological research, Dordrecht, 2010. p. 177-208. DOI: https://dx. doi.org/10.1007/978-90-481-3335-2_9

BORCHERT, R.; RIVERA, G.; HAGNAUER, W. Modification of vegetative phenology in a tropical semideciduous forest by abnormal drought and rain. Biotropica, v. 34 , n. 1, p. 27-39, mar. 2002. DOI: https://dx.doi.org/10.1111/j.1744-7429.2002.tb00239.x

CAMARGO, L. Atlas de Mato Grosso: abordagem socioeconômico-ecológica. Cuiabá - MT: Entrelinhas, SECRETARIA DE ESTADO DE PLANEJAMENTO E COORDENAÇÃO GERAL (SEPLAN), 2011. 96 p. 
CAMARGO, A. P. Aptidão climática para a heveicultura no Brasil. Ecossistema, Espírito Santo do Pinhal, v. 1, n. 1, p. 6-14, 1976.

CHAVEZ JUNIOR, P. S. An improved dark-object subtraction technique for atmospheric scattering correction of multispectral data. Remote Sensing of Environment, v. 24, n. 3, p. 459-479, abr. 1988. DOI: https://dx.doi.org/10.1016/0034-4257(88)90019-3

CHANDRASHEKAR， T. R.; NAZEER, M. A.; MARATTUKALAM, J. G.; PRAKASH, G. P.; ANNAMALAINATHAN, K.; THOMAS, J. An analysis of growth and drought tolerance in rubber during the immature phase in a dry subhumid climate. Experimental Agriculture, Cambridge, v. 34, n. 3, p. 287-300, jul. 1998 DOI: https://dx.doi.org/10.1017/S001 4479798343045

CHANDRASHEKAR, T. R.; VARGHESE, Y. A.; ALICE, J.; SAILAJADEVI, T.; SARASWATHYAMMA, C. K.; VIJAYAKUMAR, K. R. Growth pattern of rubber trees (Hevea brasiliensis) in a tropical humid climate in India. Journal of Rubber Research, v. 5, n. 3, p. 191-198, 2002.

ELLIOTT, S.; BAKER, P. J.; BORCHERT, R. Leaf flushing during the dry season: the paradox of Asian monsoon forests. Global Ecology and Biogeography, v. 15, n. 3, p. 248-257, mai. 2006. DOI: https://dx.doi.org/10.1111/j. 1466-822x.2006.00213.x

FONTANA, D. C. Utilização do Índice de Vegetação Global para o monitoramento da Vegetação e estimativa de elementos agrometeorológicos no Estado do Rio Grande do Sul. 1995. 133f. Tese (Doutorado em Fitotecnia) - Universidade Federal do Rio Grande do Sul, Faculdade de Agronomia. Porto Alegre, 1995.

FURTADO, E. L. Comportamento de cultivares de seringueira (Hevea spp.) frente ao Mal das folhas na região do Vale do Ribeira - SP. 1996. 79 p. Tese (Doutorado em Fitopatologia) - Escola Superior de Agricultura Luiz de Queiroz, Universidade de São Paulo Piracicaba, 1996.

FURTADO, E. L.; MENTEN, J. O. M.; PASSOS, J. R. Intensidade do Mal das Folhas em plantas jovens e adultas de seis clones de seringueira na região do Vale do Ribeira. Tropical Plant Pathology, Brasília, v. 33, n. 2, p. 130137, 2008. DOI: https://dx.doi.org/10.1590/S198256762008000200007

GASPAROTTO, L.; SANTOS, A. F.; PEREIRA, J. C. R.; FERREIRA, F. A. Doenças da seringueira no Brasil. Ed. Brasilia: EMBRAPA-SPI, 1997. 168 p.

GUARDIOLA-CLARAMONTE, M.; TROCH, P. A.; ZIEGLER, A. D.; GIAMBELLUCA, T. W.; VOGLER, J. B.; NULLET, M. A. Local hydrologic effects of introducing non-native vegetation in a tropical catchment. Ecohydrology, v. 1, n. 1, p. 13-22, 2008. DOI: https://dx.doi.org/10.1002/eco.3

HALLÉ, F.; OLDEMAN, R. A.; TOMLINSON, P. B Tropical trees and forest. Ed. Berlin: Springer-Verlag, 1978. 429 p. DOI: https://dx.doi.org/10.1007/978-3-642-8 1190-6

KIM, Y.; HUERTE, A. R.; MIURA, T.; JIANG, Z. Spectral compatibility of vegetation indices across sensors: band decomposition analysis with Hyperion data. Journal of Applied Remote Sensing, v. 4, n. 1, 43520, 2010. DOI: https://dx.doi.org/10.1117/1.3400635
MOISE, E.; RAYMOND, J.; KUHN, J. R. Properties of the Diffuse Neutral Helium in the Inner Heliosphere. The Astrophysical Journal, v. 722, n. 2, p. 1411-1415, 2010. DOI: https://dx.doi.org/10.1088/0004-637X/722/2/ 1411

OliVEIRA, A. H.; SILVA, M. A.; SILVA, M. L. N.; AVANZI, J. C.; CURI, N.; LIMA, G. C.; PEREIRA, P. H. Caracterização ambiental e predição dos teores de matéria orgânica do solo na Sub-Bacia do Salto, Extrema, MG. Semina: Ciências Agrárias, Londrina, v. 33, n. 1, p. 143154, 2012. DOI: http://dx.doi.org/10.5433/1679-035 $9.2012 \mathrm{v} 33 \mathrm{n} 1 \mathrm{p} 143$

ORTOLANI, A. A. Agroclimatologia e o cultivo da seringueira. In: SIMPÓSIO SOBRE A CULTURA DA SERINGUEIRA NO ESTADO DE SÃO PAULO, 1986, Piracicaba. Anais. Campinas: Fundação Cargill, 1986. p. $11-32$.

PRIYADARSHAN, P. M. Breeding Hevea brasiliensis for environmental constraints. Advances in Agronomy, v. 79, p. 351-400, 2003. DOI: https://dx.doi.org/10.1016/S0 065-2113(02)79007-X

PINHEIRO, E.; PINHEIRO, F. S. V. A. Heveicultura em área de escape. In: ALVARENGA, A. P.; CARMO, C. A. F. S. (Eds). Seringueira, Viçosa, MG: Epamig, 2014. p. 463488.

RAJ, S.; DAS, G.; POTHEN, J.; DEY S. K. Relationship between latex yield of Hevea brasiliensis and antecedent environmental parameters. International Journal of Biometeorology, v. 49, n. 3, p. 189-196, 2005. DOI: https://dx.doi.org/10.1007/s00484-004-0222-6

RAO, P. S.; SARASWATHYAMMA, C. K.; SETHURAJ, M. R. Studies on the relationship between yield and meteorological parameters of para rubber tree (Hevea brasiliensis). Agricultural and Forest Meteorology, v. 90, n. 3, p. 235-245, 1998. DOI: https://dx.doi.org/10.101 6/S0168-1923(98)00051-3.

RIVERA, G.; ELLIOTT, S.; CALDAS, L. S.; NICOLOSSI, G.; CORADIN, V. T. R.; BORCHERT, R. Increasing daylength induces spring flushing of tropical dry forest trees in the absence of rain. Trees, v. 16, n. 7, p. 445-456, 2002. DOI: https://dx.doi.org/10.1007/s00468-00201 85-3

ROUSE JUNIOR, J. W.; HAAS, R. H.; SCHEEL, J. A.; DEERING, D. W.; HARLAN, J. C. Monitoring the vernal advancement of retrogradation (greenwave effect) of natural vegetation. Greenbelt: NASA/GSFC. 1974. 371p.

ROSSMANN, H. Produção global de borracha natural aumenta 11\% em um ano. 21/07/2017. Disponível em: $\mathrm{http}: / /$ borrachanatural.agr.br/cms/index.php?option=com content\&task $=$ view\&id $=24731 \&$ Itemid $=10$ Acesso em 28-06-2018

SAMBUGARO, R. Caracterização anatômica foliar de clones de seringueira (Hevea spp.) visando resistência ao Microcyclus ulei. 2003. 61 f. Dissertação (Mestrado em Agronomia). Universidade Estadual Paulista "Júlio de Mesquita Filho", Botucatu, 2003.

SAMBUGARO, R. Estágios foliares, fenologia da seringueira (Hevea spp.) e interação com Microcyclus ulei (mal das folhas). 2007. 94 f. Tese (Doutorado em Agronomia) - Universidade Estadual Paulista "Júlio de Mesquita Filho", Botucatu, 2007.

SANTOS, R. S.; SILVA, J. M. Dinâmica populacional do parasitoide de ovos Erythmelus tingitiphagus (Hymenoptera: Mymaridae) em clone de seringueira, em 
Itiquira, MT. Revista Árvore, Viçosa, v. 37, n. 2, p. 237244, 2013.

SOUZA, I. A. Avaliação de clones de seringueira (Hevea spp.) em Piracicaba-SP. 2007. 71 p. Dissertação (Mestrado em Agronomia) - Universidade de São Paulo, Piracicaba, 2007. 